This manuscript is a non-peer reviered preprint submitted to EarthArXiv.

It has been submitted to Paleoceanography and Paleoclimatology.

Copyright in this work may be transferred without further notice.

Twitter handles of the authors are @mattjohenry and @GeoffVallis.

\title{
Different Pathways to an Early Eocene Climate
}

\author{
Matthew Henry ${ }^{1}$ and Geoffrey K. Vallis ${ }^{1}$ \\ ${ }^{1}$ Department of Mathematics, University of Exeter, Exeter, UK
}

\section{Key Points:}

- We use a flexible climate model to test the sensitivity of the Eocene climate to changes in $\mathrm{CO}_{2}$ concentration, land surface, and clouds.

- Comparisons of simulations with proxies for the seasonality of Arctic land temperature provide strong constraints on the Eocene climate.

- Our simulations show that there is more than one pathway to simulating a climate consistent with current Eocene proxy data. 


\begin{abstract}
The early Eocene was characterised by much higher temperatures and a smaller equator-topole surface temperature gradient than today. Comprehensive climate models have been reasonably successful in simulating many features of that climate in the annual average. However, good simulations of the seasonal variations, and in particular the much reduced Arctic land temperature seasonality and associated much warmer winters, have proven more difficult. Further, aside from an increased level of greenhouse gases, it remains unclear what the key processes are that give rise to an Eocene climate, and whether there is a unique combination of factors that leads to agreement with available proxies. Here we use a very flexible General Circulation Model to examine the sensitivity of the modelled climate to differences in $\mathrm{CO}_{2}$ concentration, land surface properties, ocean heat transport, and cloud extent and thickness. Even in the absence of ice or changes in cloudiness, increasing the $\mathrm{CO}_{2}$ concentration leads to a polaramplified surface temperature change because of increased water vapour and the lack of convection at high latitudes. Additional low clouds over Arctic land generally decreases summer temperatures and, except at very high $\mathrm{CO}_{2}$ levels, increases winter temperatures, thus helping achieve an Eocene climate. An increase in the land surface heat capacity, plausible given large changes in vegetation and landscape, also decreases the Arctic land seasonality. In general, various different combinations of factors - high $\mathrm{CO}_{2}$ levels, changes in low-level clouds, and an increase in land surface heat capacity - can lead to a simulation consistent with current proxy data.
\end{abstract}

\title{
Plain Language Summary
}

During the early Eocene, some 50 million years ago, the Earth was approximately 13 degrees warmer and the equator-to-pole surface temperature difference was much smaller than that of today. We now have proxy data on the surface temperature at different latitudes and the seasonality of the surface temperature (for land at high-latitudes), the amount of carbon dioxide in the air, the nature of the vegetation, and the land configuration. However, much of this data is quite uncertain. Modern climate models have been used to estimate what the Eocene climate was like, but they are complicated to use, hard to understand, and in some ways are tuned to the present climate. Here we use a simpler, more flexible climate model to simulate the Eocene climate and examine how differences in the $\mathrm{CO}_{2}$ concentration, land surface properties, ocean heat transport, and cloud extent and thickness affect the simulated climate. We find that different combinations of $\mathrm{CO}_{2}$ concentration, surface albedo, cloudiness and surface heat capacity of land can lead to simulations that are within estimated values from the data, suggesting there are multiple pathways to simulating a climate consistent with what is currently known about the Eocene.

\section{Introduction}

The early Eocene was one of the warmest climates over the last 60 million years, with global-mean temperatures some 13 degrees higher than today. In addition to its intrinsic interest, the climate may provide lessons for our future as the warmest simulations of the high emission scenarios lead to similar levels of warming by 2300 (Burke et al., 2018). The carbon dioxide $\left(\mathrm{CO}_{2}\right)$ concentration during the Eocene is rather uncertain, but estimates usually put it at between about 1200 and 2500 ppmv, which is approximately 4 to 9 times pre-industrial levels (Anagnostou et al., 2020), although it is possible it may have been higher. The equatorto-pole surface temperature gradient was remarkably low, with annual-mean temperatures around $35^{\circ} \mathrm{C}$ at the equator and $15^{\circ} \mathrm{C}$ at high latitudes (Zhu et al., 2019). Additionally, the high-latitude surface temperature seasonality was much reduced, with winter temperatures seemingly above $0^{\circ} \mathrm{C}$ and summer temperatures around $25^{\circ} \mathrm{C}$ in Arctic Canada at $79^{\circ} \mathrm{N}$ (Eberle et al., 2010). We have clues on the early Eocene hydrological cycle from fossils and sediments: though these proxies are uncertain, both comprehensive model simulations and proxies support an intensified hydrological cycle and increased meridional latent heat transport (Carmichael et al., 2016). 
Our understanding of past warm climates may also inform our understanding of potentially warm future climates: Tierney et al. (2020), for example, argue that since the Equilibrium Climate Sensitivity (ECS) increases as the base state climate warms from today's value, modelling the Eocene climate can provide key constraints on the range of plausible ECS values.

Proxy measurements of Eocene temperatures have consistently suggested that high latitudes warmed more than low latitudes (Huber \& Caballero, 2011), and a similar effect occurs in simulations of anthropogenic global warming (Holland \& Bitz, 2003). The mechanisms of polar amplification are now becoming more clear, as reviewed by Taylor et al. (2021). While the surface albedo feedback from melting snow and sea ice is an important component of polar amplification, models show polar amplification even when this process is turned off (Graversen \& Wang, 2009, for example). The water vapor feedback leads to increased atmospheric humidity (and can also be triggered by an increase in absorbed solar radiation). The increase in moisture causes amplified Arctic warming through its greenhouse effect which directly leads to surface-enhanced Arctic warming in the absence of convection (Cronin \& Jansen, 2016; Henry et al., 2021), and through increased moist atmospheric energy transport convergence at high latitudes (Hwang et al., 2011). The picture was confused because early proxy reconstructions of Eocene climates suggested that temperatures at low latitudes increased far less than temperatures at high latitudes, so much so that climate models struggled to represent the apparent much reduced equator-to-pole temperature gradient (Huber et al., 2003, for example). However, more recent estimates of tropical temperatures seem to indicate low-latitude temperatures were higher than was previously estimated (Pearson et al., 2007), albeit with large error bars, and recent climate models show a better proxy-model match in surface temperature gradient (D. Lunt et al., 2020). Thus, at least on the annual average, it seems there may in fact no longer be a large discrepancy between climate models and Eocene proxies. The generally-accepted reason for the high overall temperature in the Eocene is high $\mathrm{CO}_{2}$ levels, and climate models give fair agreement with proxies (Huber \& Caballero, 2011), albeit often with higher levels of $\mathrm{CO}_{2}$ than are now thought to have existed (Anagnostou et al., 2020). The required level of $\mathrm{CO}_{2}$ needed for such high temperatures could be reduced if there were an increase in absorbed solar radiation (i.e., a reduced planetary albedo). This might be achieved, for example, through a decrease in aerosol production leading to a decrease in cloud condensation nuclei and a reduction in cloud cover (Kiehl \& Shields, 2013; Carlson \& Caballero, 2017). The warming from $\mathrm{CO}_{2}$ could also potentially lead to a reduction in cloud cover which reduces the planetary albedo (Zhu et al., 2019).

Although the annual average Eocene temperature can arguably be reproduced by climate models, much more difficulty arises when trying to understand the seasonality of Arctic temperatures. Various proxies (Greenwood \& Wing, 1995; Eberle et al., 2010) indicate a much lower seasonal variation of temperature and suggest that, even over land, temperatures did not fall below $0^{\circ} \mathrm{C}$ for extended periods of time. Various mechanisms have been proposed to increase Arctic surface warming in climate models, such as increased stratospheric clouds (Sloan $\&$ Pollard, 1998), an Arctic convective cloud feedback (Abbot \& Tziperman, 2008) and Arctic low land clouds (Cronin et al., 2017; Hu et al., 2018), but how these mechanisms quantitatively fit in the overall picture of the Eocene climate is less well understood, falling more under the remit of comprehensive climate models. Thus, whereas recent model simulations of the early Eocene, as described by D. Lunt et al. (2020), consistently ascribe the general increase in temperature to increased levels of $\mathrm{CO}_{2}$ (as expected), the mechanisms of polar amplification and winter warmth are less clear. Even in cases where those simulations match the proxies we do not always understand why: for example, to what degree is the dominant effect one of a change in cloud cover or type, or a change in surface boundary condition, or a change in the general circulation, or some other effect?

Our goal in this paper is to clarify the conditions required to reproduce an Eocene climate, with particular attention to the seasonal cycle and the maintenance of relatively warm winters over Arctic land. To this end we use a very flexible GCM, configured with Eocene land and topography, that enables us to independently vary $\mathrm{CO}_{2}$ levels, cloud distributions, ocean 
heat transport, and various land-surface parameters. We thereby seek to understand how these processes, separately and together, affect the global-mean temperature, the equator-to-pole surface temperature gradient, and the seasonality in Arctic land temperature. We begin with a description of the model itself (Section 2), and follow this with a description of experiments in which we change the surface boundary conditions (Section 3), the clouds (Section 4), the land surface heat capacity (Section 5), and ocean heat transport (Section 6).

\section{Model and Reference Simulations}

We construct our models using the Isca climate modeling framework (Vallis et al., 2018) configured with no sea ice, a slab mixed-layer ocean boundary condition, and a simple representation of land and topography following Eocene-like continental outlines taken from comprehensive climate model simulations of the Eocene (D. J. Lunt et al., 2021). Meridional ocean heat transport is represented by imposing a q-flux, as described further in Section 6, although in many simulations this is set to zero. The cloud scheme diagnoses large scale clouds from the relative humidity, with adjustments for marine low stratus clouds and polar clouds (Liu et al., 2020). The effective radius of liquid and ice cloud droplets is set to 14 and 25 microns respectively, and the in-cloud liquid water mixing ratio is set to $0.18 \mathrm{~g} / \mathrm{kg}$. These parameters are unchanged for all the experiments presented in this manuscript. We impose a seasonal cycle of insolation and use the comprehensive SOCRATES radiation scheme for both solar and infra-red radiation (Manners et al., 2017; Thomson \& Vallis, 2019), which maintains good accuracy for $\mathrm{CO}_{2}$ levels up to a factor of 16 or more than present values. The surface albedo is set to 0.075 over ocean and 0.15 over land which is similar to comprehensive model simulations of the Eocene (D. J. Lunt et al., 2021). Land also differs from oceans by its heat capacity, which we set to 0.2 meters equivalent water depth for continents (Merlis et al., 2013) and 20 meters for oceans, by the roughness constant, which is set to be 10 times higher over land than ocean, and by the land evaporative resistance which is set to 0.5 (parameter $\beta$ in equation 10 of Vallis et al. (2018)). We use the Eocene's land distribution (the contour is visible in fig. 1), and notice that most modern day continents are recognizable, though the continental configuration may have an impact on ocean circulation. Simulations are run at spectral T42 resolution, which corresponds to approximately 2.8 degrees resolution at the equator. Convection is calculated using a simplified Betts-Miller convection scheme (Frierson, 2007). Large scale condensation is parameterized such that relative humidity does not exceed one and condensed water immediately returns to the surface, and the cloud distribution is not directly coupled to the precipitation.

We first describe five reference simulations with a fixed set of control parameters in which $\mathrm{CO}_{2}$ concentrations are set to $300 \mathrm{ppm}, 900 \mathrm{ppm}(3 \times 300 \mathrm{ppm}), 1800 \mathrm{ppm}(6 \times 300 \mathrm{ppm}), 2700 \mathrm{ppm}$ $(9 \times 300 \mathrm{ppm})$, and $3600 \mathrm{ppm}(12 \times 300 \mathrm{ppm})$. Following that we discuss a set of experiments where the surface albedo and land evaporative resistance are modified, a set where we prescribe various high-latitude cloud distributions, and a set where we reduce the land's surface heat capacity. Finally, we test the importance of ocean heat transport by prescribing a meridional heat transport in the slab ocean. The list of experiments, parameters explored, relevant manuscript sections, and abbreviations used in the figures are summarized in Table 1.

Figure 1 shows the annual-mean and winter (December, January, and February mean (DJF)) surface temperature for the $300 \mathrm{ppm}$ and $3600 \mathrm{ppm}$ simulations. At $300 \mathrm{ppm}$, the winter temperatures reach below $-30^{\circ} \mathrm{C}$ in parts of the Arctic land whereas at $3600 \mathrm{ppm}$, the winter temperatures are above zero almost over the whole Arctic land surface. At $2700 \mathrm{ppm}$ the temperatures fall below zero for periods in winter, as seen in fig. 2, although given the uncertainties in the proxies it is difficult to be definitive as to whether this falls outside of bounds of the observations.

The zonal-mean land and ocean surface temperature are compared with proxies in fig. $2 \mathrm{a}$ and $\mathrm{b}$. The annual-mean surface temperature is more or less within the proxy range for land for $\mathrm{CO}_{2}$ concentrations above $1800 \mathrm{ppm}$. While some proxy ocean temperature points are warmer 
Table 1. List of GCM experiments with type of experiment, the explored parameter range, the relevant section number, and the abbreviation used in the figures. Note that each experiment type has been run with $\mathrm{CO}_{2}$ concentrations set to $1,3,6,9$, and 12 times preindustrial levels.

\begin{tabular}{|c|c|c|c|}
\hline Experiment type & Parameter range & Section & Abbreviation \\
\hline Control simulations & $\mathrm{CO}_{2}$ set to $1,3,6,9,12 \mathrm{x}$ preindustrial level $(300 \mathrm{ppm})$ & 2 & $\mathrm{CO}_{2}$ only \\
\hline Surface albedo & Set to 0.05 over ocean and 0.10 over land (instead of 0.075 and 0.15 respectively) & 3 & alb 0.5 \\
\hline Land evaporative resistance & Set to 1 instead of 0.5 & 3 & evap 1 \\
\hline High-lat ocean high clouds & Cloud fraction min set to $0.25,0.5$, and 0.75 between 300 and $500 \mathrm{hPa}$ over high-lat ocean & 4 & high ocean \\
\hline High-lat land low clouds & Cloud fraction min set to 0.35 and 0.7 between 600 and $1000 \mathrm{hPa}$ over high-lat land & 4 & low land \\
\hline Increased stratospheric clouds & Cloud fraction min set to 0.2 between 0 and $200 \mathrm{hPa}$ over high-latitudes & 4 & strat \\
\hline No stratospheric clouds & Cloud fraction max set to 0 between 0 and $200 \mathrm{hPa}$ over high-latitudes & 4 & no strat \\
\hline Land surface heat capacity & Set to $0.1 \mathrm{x}$ ocean surface heat capacity (instead of 0.01 ) & 5 & 0.1 landhc \\
\hline Ocean heat transport & $0,1,2 \mathrm{x}$ prescribed meridional ocean heat transport & 6 & $0,1,2 \mathrm{x}$ oht \\
\hline
\end{tabular}
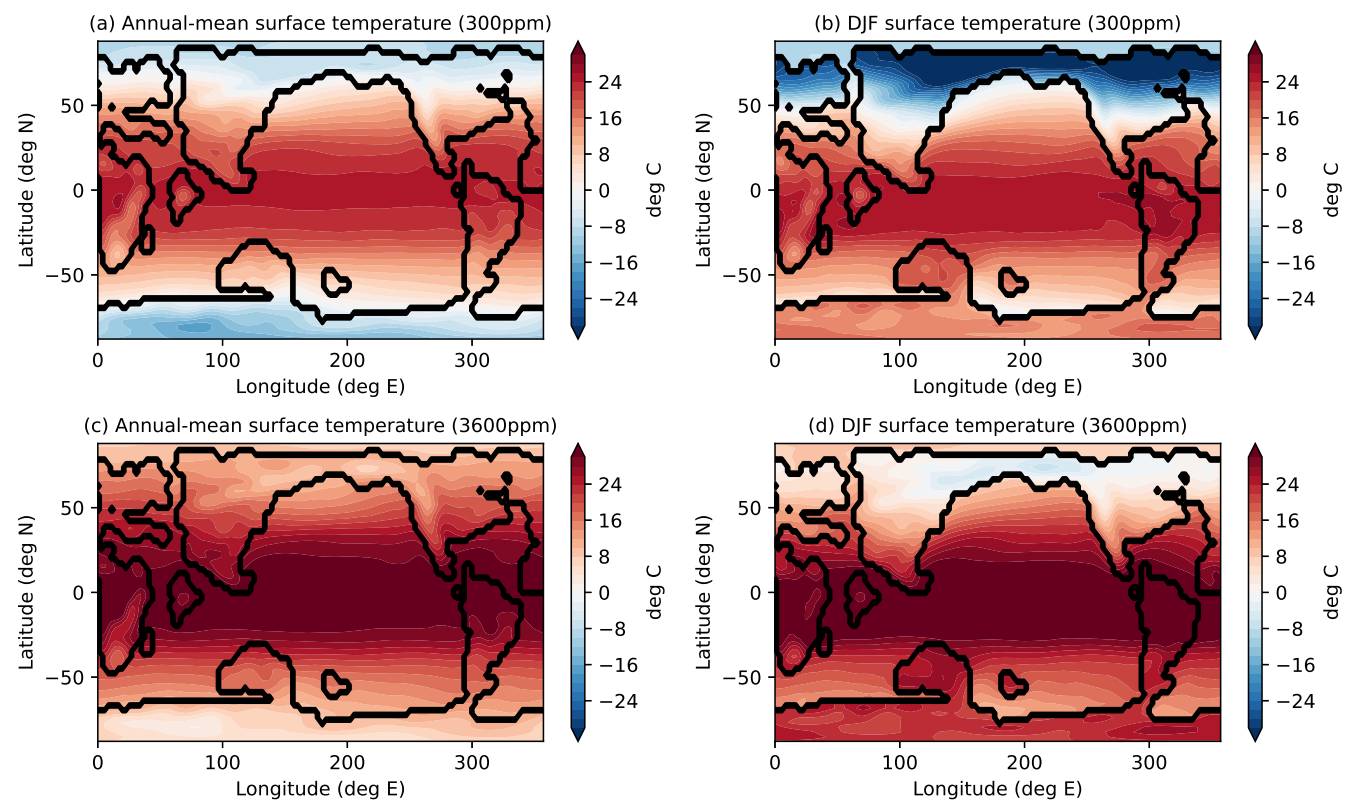

Figure 1. Surface temperatures in control simulations with present-day and very high $\mathrm{CO}_{2}$ levels. Annualmean surface temperature $(a, c)$ and December-January-February (DJF) surface temperature $(b, d)$ for the $300 \mathrm{ppm}(\mathrm{a}, \mathrm{b})$ and $3600 \mathrm{ppm}(\mathrm{c}, \mathrm{d})$ simulations, as labelled.

than all simulations, simulations with $\mathrm{CO}_{2}$ concentration above $2700 \mathrm{ppm}$ yield a reasonable match with proxies. The seasonality of Arctic land temperature (fig. 2c) shows that winter land temperatures are more sensitive to an increase in $\mathrm{CO}_{2}$ (Henry \& Vallis, 2021b) and that even at $3600 \mathrm{ppm}$, the land temperature is still below 0 degrees $\mathrm{C}$ in winter. The atmospheric temperature change in the Arctic is surface enhanced in winter and top-heavy in the summer (fig. $2 \mathrm{~d}, \mathrm{e}$, and $\mathrm{f}$ ). In summer, the land surface gets warm enough to trigger convection which pins the atmospheric temperature to the moist adiabat, whereas in winter the absence of convection leads to surface-enhanced warming. This was explained for similar simulations without clouds in Henry et al. (2021).

As noted in the introduction, atmospheric models produce polar amplification - meaning an enhanced warming at and near the the surface at high latitudes - when $\mathrm{CO}_{2}$ is increased, even without changes in ice cover. To understand this, suppose first that the vertically aver- 

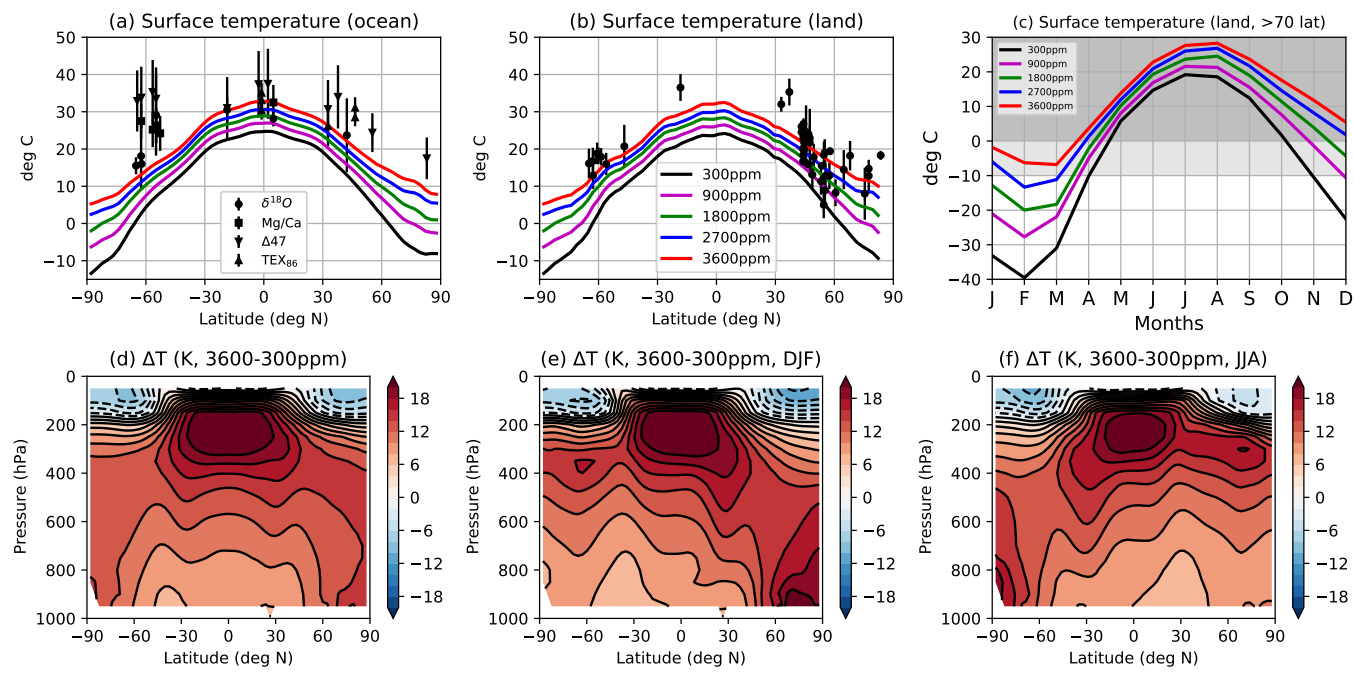

Figure 2. Surface temperature for various Eocene simulations. Annual-mean ocean (a) and land (b) surface temperature for control simulations (all $\mathrm{CO}_{2}$ levels) compared with proxies (symbols). Seasonality of Arctic (poleward of 70 degrees North) land surface temperature for control simulations (c), with proxy-derived estimate in grey. The dark grey represents the values derived from Eberle et al. (2010), and the light grey is a larger interval to account for the uncertainty in proxy values. The proxy values for ocean surface temperatures are from Zhu et al. (2019) and the land surface temperatures are from Huber and Caballero (2011). Atmospheric temperature change for the difference between the $300 \mathrm{ppm}$ and $3600 \mathrm{ppm}$ simulations in the annual-mean (d), December-January-February (DJF) (e), and June-July-August (JJA) (f), as labelled.

aged increase in temperature is roughly constant with latitude. The presence of convection in the tropics pins the atmospheric temperature profile to the moist adiabat; which means the temperature increase is largest in the upper troposphere and lowest near the surface. That effect is absent at high latitudes, leading to an effective low-level polar amplification. In addition, the overall increase in water vapor due to a higher temperature and increase in latent heat transport leads to bottom-heavy atmospheric temperature change at high latitudes (Henry et al., 2021).

In addition to polar amplification, the increased temperatures that results from the additional $\mathrm{CO}_{2}$ forcing alone reduces the seasonality of Arctic land temperature due to the small heat capacity of land (Henry \& Vallis, 2021b). This effect arises from the nonlinearity of the temperature dependence of surface longwave emission, which is proportional to $\sigma T_{S}^{4}$, where $T_{S}$ is the surface temperature. Surfaces at low temperature need to warm more than those at high temperature in order to achieve the same increase in emission, leading to a larger increase in surface temperature in winter than in summer. The seasonality is naturally larger over land than ocean, because of the larger heat capacity of the ocean, so the effect is much more pronounced over land. Increases in evaporation over land in summer also contribute to the winteramplified pattern of surface temperature change. Indeed, surface evaporation is calculated as proportional to the difference between saturation vapor pressure calculated using the surface temperature and the humidity of the lowest atmospheric level (Vallis et al., 2018), and the former increases faster than the latter with warming in summer over land (Henry \& Vallis, 2021b).

The combined effects of polar amplification and a reduction in seasonality of Arctic land temperature are observed in all high- $\mathrm{CO} 2$ simulations, regardless of the presence or otherwise of sea ice or clouds. The same effect is present in extended RCP8.5 simulations before and after sea ice disappears in comprehensive models (Henry \& Vallis, 2021b). These effects are the dominant mechanisms leading to increased high-latitude surface temperatures over land in 
winter, and go a long way toward explaining the proxy measurements indicating the lack of extended periods of freezing in winter. However, in and of themselves they may be insufficient for us to be confident we have good agreement with the proxies, and for that reason we explore what additional effects may be important.

\section{Modifying surface boundary conditions}

We now explore the effects of changing the surface boundary conditions. In one set of experiments, the surface albedo is set to 0.05 over ocean and 0.10 over land (instead of 0.075 and 0.15 respectively in the control simulations). And in another set of experiments, the evaporative resistance parameter is set to 1 enabling the land to evaporate as efficiently as the ocean, mimicking a swamp-like surface. Figure $3 \mathrm{a}$ and $\mathrm{b}$ show the ocean and land surface temperature respectively for these simulations. Reducing the albedo means that, at $2700 \mathrm{ppm}$, the surface temperature is similar to the reference simulation at $3600 \mathrm{ppm}$ and matches the proxies (fig. 3a and b). The monthly temperature minimum, maximum, and temperature range of Arctic (poleward of 70 degrees North) land are given in fig. 3c, d, and e respectively. The dark grey boxes denote the proxy-derived values (Eberle et al., 2010), and the light grey boxes are a feasible extension of these proxy-derived values as they are quite uncertain. The Arctic land temperature minimum only reaches above 0 degrees $\mathrm{C}$ for $12 \times 300 \mathrm{ppm}$ and a lower surface albedo, the Arctic land temperature maximum however is within the proxy-derived range for all simulations. Decreasing the surface albedo leads to warmer Arctic land temperatures in both winter and summer, whereas increasing surface evaporation leads to cooler Arctic land temperatures year-round.

Figure $3 \mathrm{f}$ and $\mathrm{g}$ show the difference in top-of-atmosphere (TOA) net shortwave radiation and cloud radiative forcing respectively between the reference $300 \mathrm{ppm}$ simulation and the increased land evaporation (blue) and decreased albedo (red) $300 \mathrm{ppm}$ simulations. Figure $3 \mathrm{~h}$ shows the vertical sum of specific humidity for the same simulations. Decreasing the surface albedo leads to more shortwave radiation being absorbed at the surface, hence higher net shortwave radiation at the TOA (fig. 3f). The shortwave cloud radiative forcing depends on the albedo difference between the cloud and the surface, hence decreasing the surface albedo also leads to a tropically-amplified decrease in the cloud radiative forcing (fig. $3 \mathrm{~g}$ ) as the clouds' reflection of sunlight contributes more to the planetary albedo. Increasing surface evaporation over land leads to more low clouds over land and a more negative cloud radiative forcing and less net shortwave radiation at the TOA (fig. $3 \mathrm{f}$ and g, blue). Note that the decrease in cloud radiative forcing and net shortwave radiation at the TOA are generally higher at latitudes with more land (fig. $3 \mathrm{f}$ and g, blue). Finally, the atmosphere is moister in the simulation with a smaller surface albedo and less moist in the increased evaporation simulation (fig. 3h), which impacts winter Arctic land temperature (fig. 3c).

In summary, both changing the surface albedo and increasing land surface evaporation affect the amount of absorbed solar radiation at the TOA, hence affect the global mean and Arctic warming, as well as atmospheric humidity. Decreasing the surface albedo increases absorbed solar radiation, warms the planet, and increases atmospheric humidity. Increasing surface evaporation increases the amount of low clouds over land, which increases the amount of reflected sunlight, cools the planet, and reduces specific humidity.

\section{Effect of various Arctic cloud configurations}

Abbot and Tziperman (2008) argue that deep convection could occur over high latitude oceans in winter when they are ice-free (as is the case during the Eocene); if so, the consequent increased longwave cloud radiative forcing could help account for the warm Arctic winters. Moreover, Cronin et al. (2017) argue that, as relatively warm maritime air masses are advected over Arctic land in winter the low-cloud optical thickness increases thereby suppressing surface cooling and amplifying winter Arctic land warming. These results are supported by single column model simulations (Cronin \& Tziperman, 2015) and GCM simulations (Hu 
(a) Surface temperature (ocean)

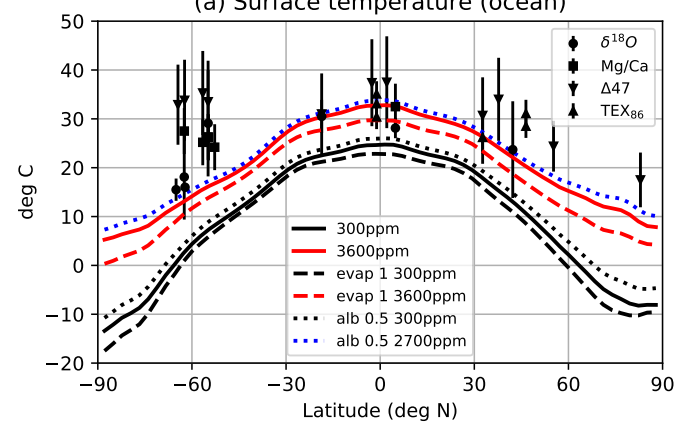

(b) Surface temperature (land)

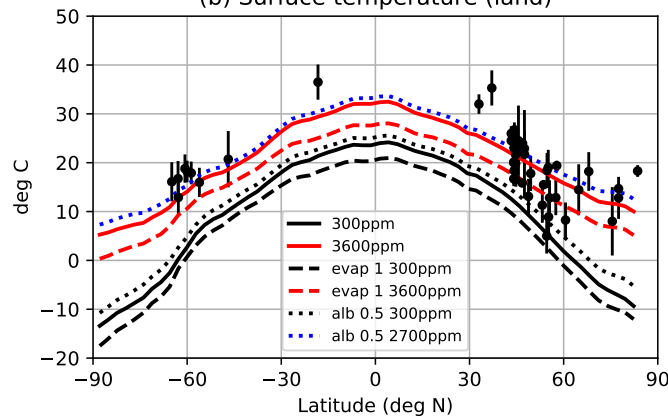

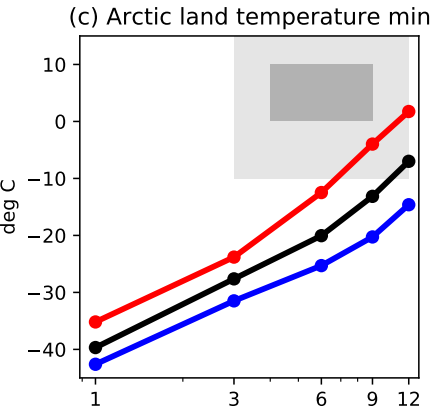

$\mathrm{CO}_{2}$ (times $300 \mathrm{ppmv}$ )

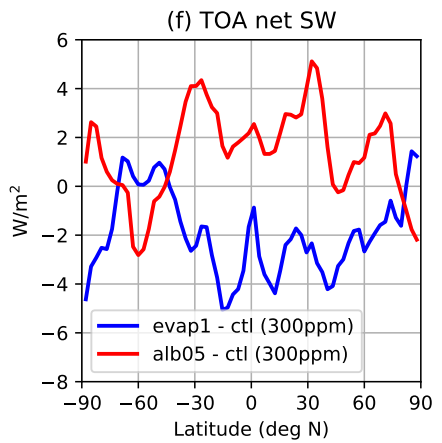

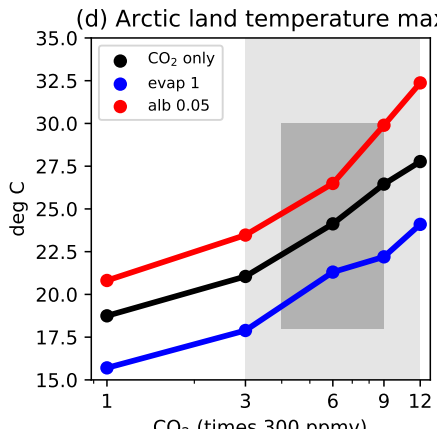

$\mathrm{CO}_{2}$ (times $300 \mathrm{ppmv}$ )

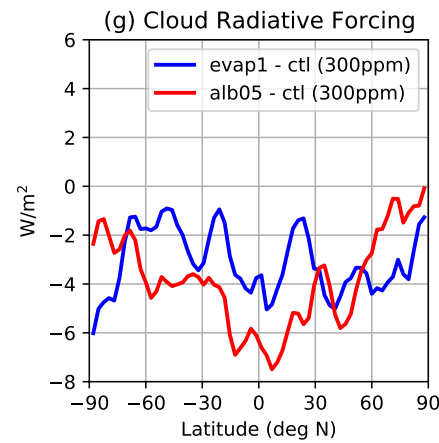

(e) Arctic land temperature range

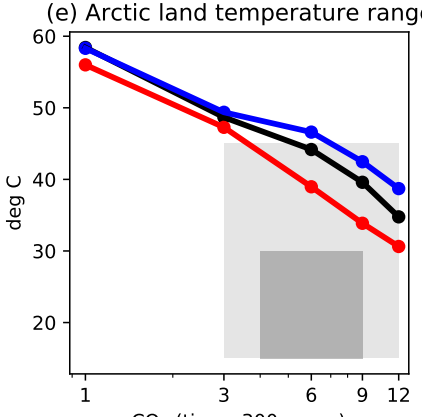

$\mathrm{CO}_{2}$ (times $300 \mathrm{ppmv}$ )

(h) Vertical sum of humidity

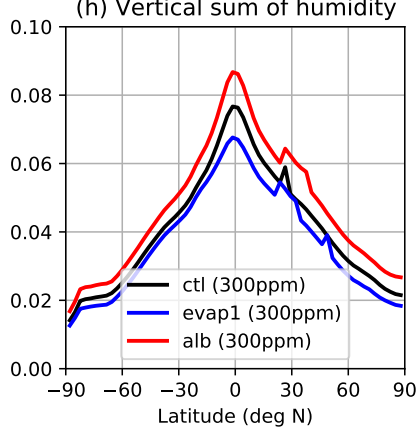

Figure 3. Simulations with modified land evaporative resistance and modified surface albedo. Ocean (a) and land (b) annual-mean surface temperature, and seasonality of Arctic land temperature (c,d, and e). Difference in annual-mean top-of-atmosphere net shortwave radiation ( $f$ ) and cloud radiative forcing ( $g$ ), and vertical sum of atmospheric humidity (h). In panels (a) and (b), the proxy values for ocean surface temperatures are from Zhu et al. (2019) and the land surface temperatures are from Huber and Caballero (2011). In panels (c), (d), and (e), the dark grey represents the values derived from Eberle et al. (2010), and the light grey is a larger interval to account for the uncertainty in proxy values. 
et al., 2018). Finally, for high enough $\mathrm{CO}_{2}$, Arctic stratospheric clouds can form in winter, which were hypothesized to be important in maintaining warm Arctic winters (Sloan \& Pollard, 1998). In order to test these various hypotheses as to how clouds affect Arctic warming, we prescribe increased high clouds over the Arctic ocean year-round (Abbot \& Tziperman, 2008), increased low clouds over Arctic land year-round (Cronin \& Tziperman, 2015; Cronin et al., 2017; Hu et al., 2018). In additional experiments, we prescribe additional Arctic stratospheric clouds and suppress them. At every model timestep, the minimum cloud fraction is set to a given value for a specified latitude and pressure range, such that the cloud fraction can exceed but not be below the given value. In the case where clouds are suppressed, we set the maximum value for cloud fraction for the specified latitude and pressure range.

The low land experiments consist in setting the cloud fraction minimum to be 0.35 and 0.7 for land surfaces poleward of 60 degrees between 600 and $1000 \mathrm{hPa}$. These values are consistent with values presented in $\mathrm{Hu}$ et al. (2018). For comparison, the annual-mean zonal-mean cloud fraction in the control $300 \mathrm{ppm}$ simulation is shown alongside the cloud fraction in the 0.35 and 0.7 cloud fraction minimum simulations in fig. $4 \mathrm{a}, \mathrm{b}$ and $\mathrm{c}$. The Arctic land temperature minimum, maximum, and range are given in fig. $4 \mathrm{~d}$, e, and f. The light and dark grey boxes are the same as in fig. 3. Low clouds normally have a larger effect in the visible than in the infra-red (discussed more below), and thus tend to lower the summer temperatures, as seen in fig. 4e. There is also a warming greenhouse effect, increasing the winter minimum, although this diminishes as $\mathrm{CO}_{2}$ increases and the longwave opacity of the atmosphere increases. The net effect is to reduce the seasonality of the Arctic land temperature to within the proxy bounds at $9 \times 300 \mathrm{ppm}$ and $12 \times 300 \mathrm{ppm}$, although the minimum is still a little low. The Arctic land temperature maximum is generally within proxy-derived values for values of $\mathrm{CO}_{2}$ above $3 \times 300 \mathrm{ppm}$.

The radiative effect of the imposed clouds is the difference in the top-of-atmosphere radiation budget between all-sky and clear-sky conditions with the temperature profile fixed to all-sky conditions. The difference between the radiative effect with the prescribed cloud described in the last paragraph and the reference simulation is shown in fig. $4 \mathrm{~g}$ for the $300 \mathrm{ppm}$ simulations. As is well known, low clouds generally have a larger effect in the visible than in the infrared, and hence have a cooling effect, in particular when insolation is large as in summer. In winter at high latitudes, when the insolation is small, the infra-red dominates and the additional low clouds have a warming effect. Thus, the net effect of the additional low clouds is to reduce the magnitude of the seasonal cycle. Even though the shortwave effect in summer is larger that the infra-red effect in winter, the impact on the land temperature is actually larger in winter than in summer (fig. 4h), because of the 'winter-warms-more' mechanism discussed in (Henry \& Vallis, 2021b). At high $\mathrm{CO}_{2}$, the presence of additional low clouds over land has little effect on Arctic winter land temperatures because the longwave opacity of the atmosphere is already high, though it still reduces summer temperatures through its shortwave effect (fig. 4e). Hence, at high $\mathrm{CO}_{2}$, the 'winter-warms-more' effect is still present, but the radiative effect of additional clouds in winter is a lot smaller.

The high ocean experiments consist in setting the cloud fraction minimum to $0.25,0.5$, and 0.75 for ocean surfaces poleward of 60 degrees between 300 and $500 \mathrm{hPa}$. For comparison, the annual-mean zonal-mean cloud fraction in the control $300 \mathrm{ppm}$ simulation is shown alongside the cloud fraction in the 0.25 and 0.75 cloud fraction minimum simulations in fig. $5 \mathrm{a}, \mathrm{b}$ and $\mathrm{c}$. The Arctic land temperature minimum, maximum, and range are not changed much (fig. 5d, e, and f), despite the large increase in high clouds in the 0.75 experiment (fig. 5c). The additional radiative effect of high clouds is, at least in these simulations, relatively weak in all seasons (fig. $5 \mathrm{~g}$ ). The effect is to warm in all seasons, with more warming in winter and most of that over land, because of its low surface heat capacity (fig. 5h).

Finally, the stratospheric cloud experiments consist in setting the cloud fraction minimum to 0.2 and 0 respectively poleward of 60 degrees between 0 and $200 \mathrm{hPa}$. For comparison, the annual-mean zonal-mean cloud fraction in the control $300 \mathrm{ppm}$ simulation is shown alongside the cloud fraction in the no stratospheric cloud and increased stratospheric cloud sim- 

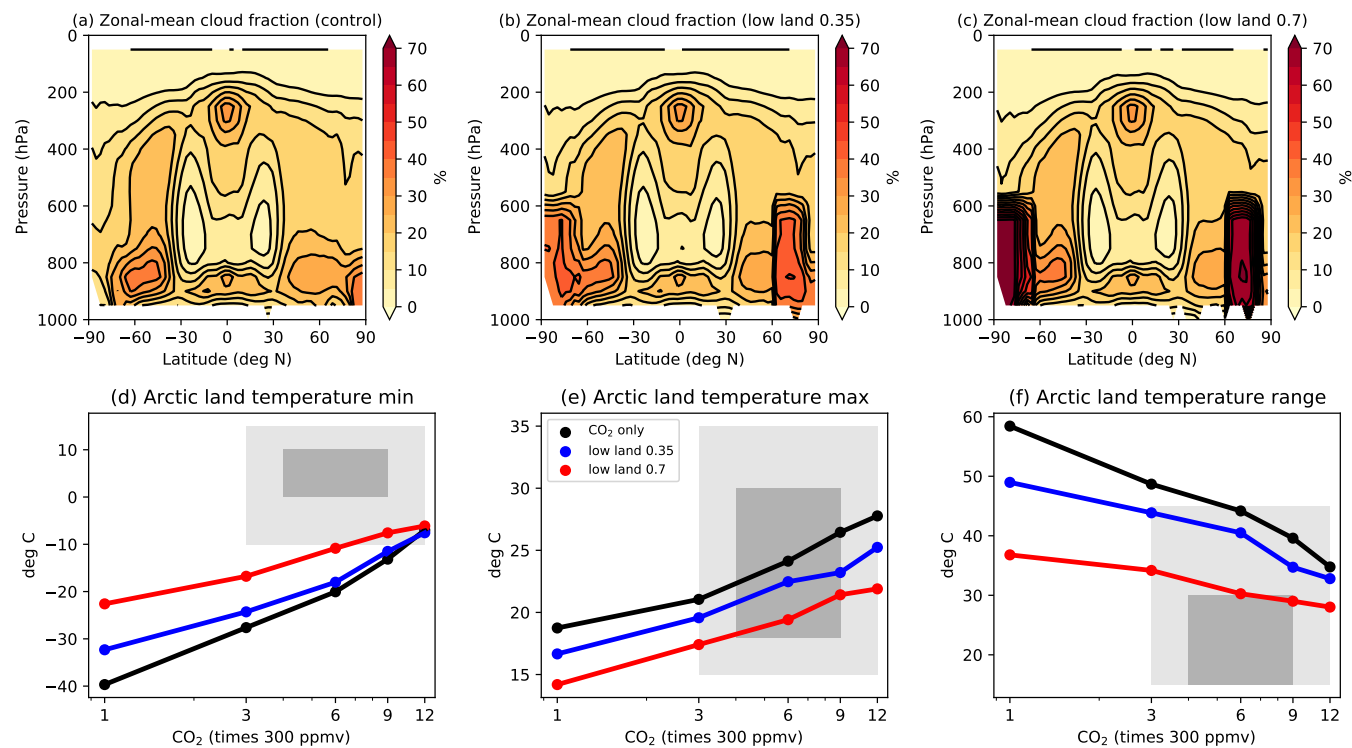

(g) Difference in radiative effect of clouds (300ppm)
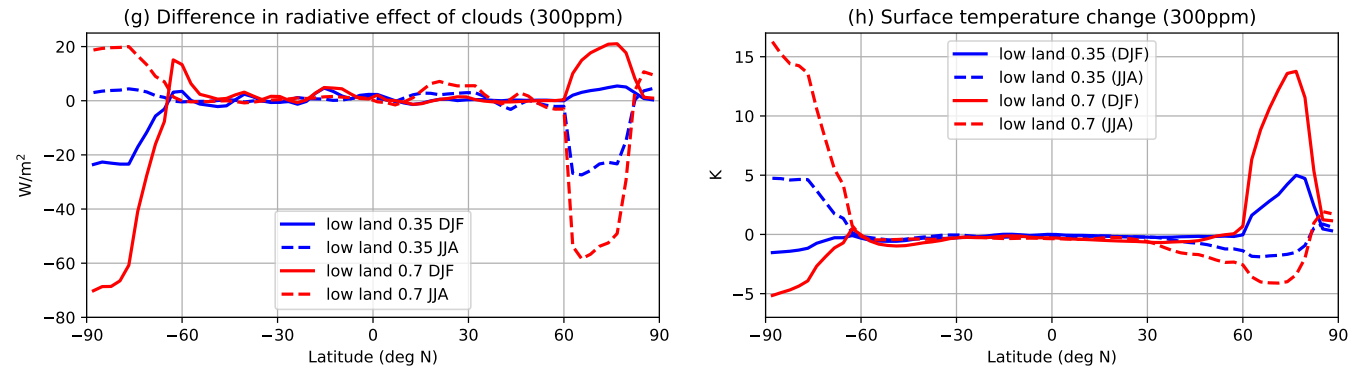

Figure 4. Prescribed additional low clouds over Arctic land experiments. Zonal-mean annual-mean cloud fraction for the control (a), 0.35 (b) and 0.7 (c) minimum high cloud fraction over Arctic ocean simulations at $300 \mathrm{ppm}$. Monthly minimum (d), maximum (e), and range (f) of Arctic land surface temperature for all three sets of simulations. The difference in radiative effect of clouds (g) and surface temperature change (h) between the prescribed cloud and control experiments at $300 \mathrm{ppm}$ for Northern hemisphere winter (DJF) and summer (JJA). In panels (d), (e), and (f), the dark grey represents the values derived from Eberle et al. (2010), and the light grey is a larger interval to account for the uncertainty in proxy values.

ulations in fig. 6a, b and c. The Arctic land temperature minimum, maximum, and range are almost unchanged (fig. 6d, e, and f). This may be because the radiative effect of these clouds is very small, at least in these simulations (fig. $6 \mathrm{~g}$ ), and hence does not change the surface temperature (fig. 6h).

\section{Modifying land surface heat capacity}

In our reference simulations, the surface heat capacity of land is equivalent to an ocean mixed layer depth of $0.2 \mathrm{~m}$, with that of ocean itself being $20 \mathrm{~m}$. The value of the land heat capacity is taken from Merlis et al. (2013): the product of specific heat capacity and density for soil is approximately 0.2 times that of the ocean, and the effective diffusion depth for soil is approximately one meter for the seasonal cycle (Pierrehumbert, 2010). Hence the equivalent depth of the land 'mixed layer', in terms of meters of water, is $0.2 \times 1=0.2 \mathrm{~m}$, a factor of 100 less than the value we use for the ocean. These values give a seasonal cycle of about 

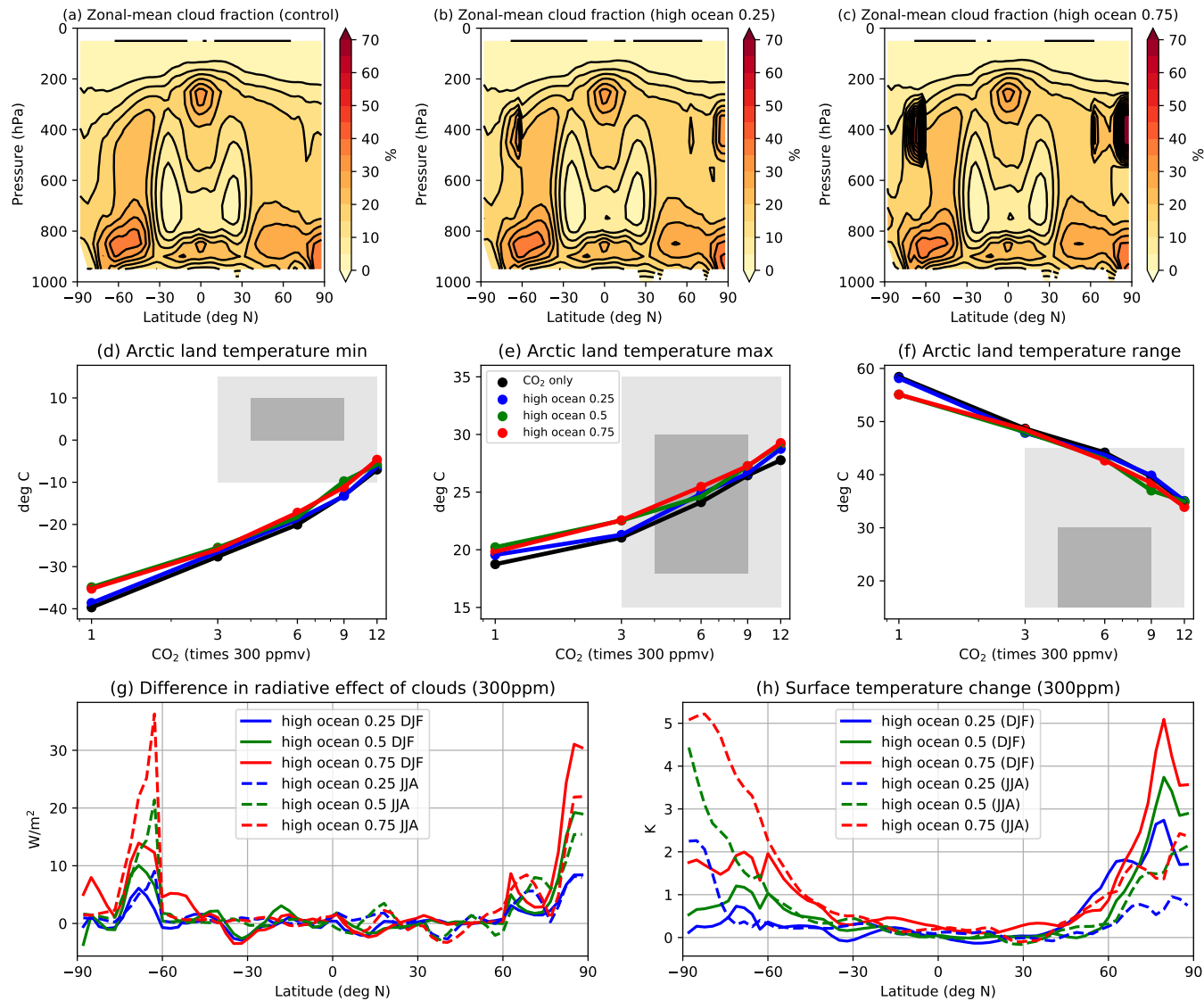

Figure 5. Prescribed additional high clouds over Arctic ocean experiments. Zonal-mean annual-mean cloud fraction for the control (a), 0.25 (b) and 0.75 (c) minimum low cloud fraction over Arctic land simulations at $300 \mathrm{ppm}$. Monthly minimum (d), maximum (e), and range (f) of Arctic land surface temperature for all four sets of simulations. The difference in radiative effect of clouds $(\mathrm{g})$ and surface temperature change $(\mathrm{h})$ between the prescribed cloud and control experiments at $300 \mathrm{ppm}$ for Northern hemisphere winter (DJF) and summer (JJA). In panels (d), (e), and (f), the dark grey represents the values derived from Eberle et al. (2010), and the light grey is a larger interval to account for the uncertainty in proxy values. 

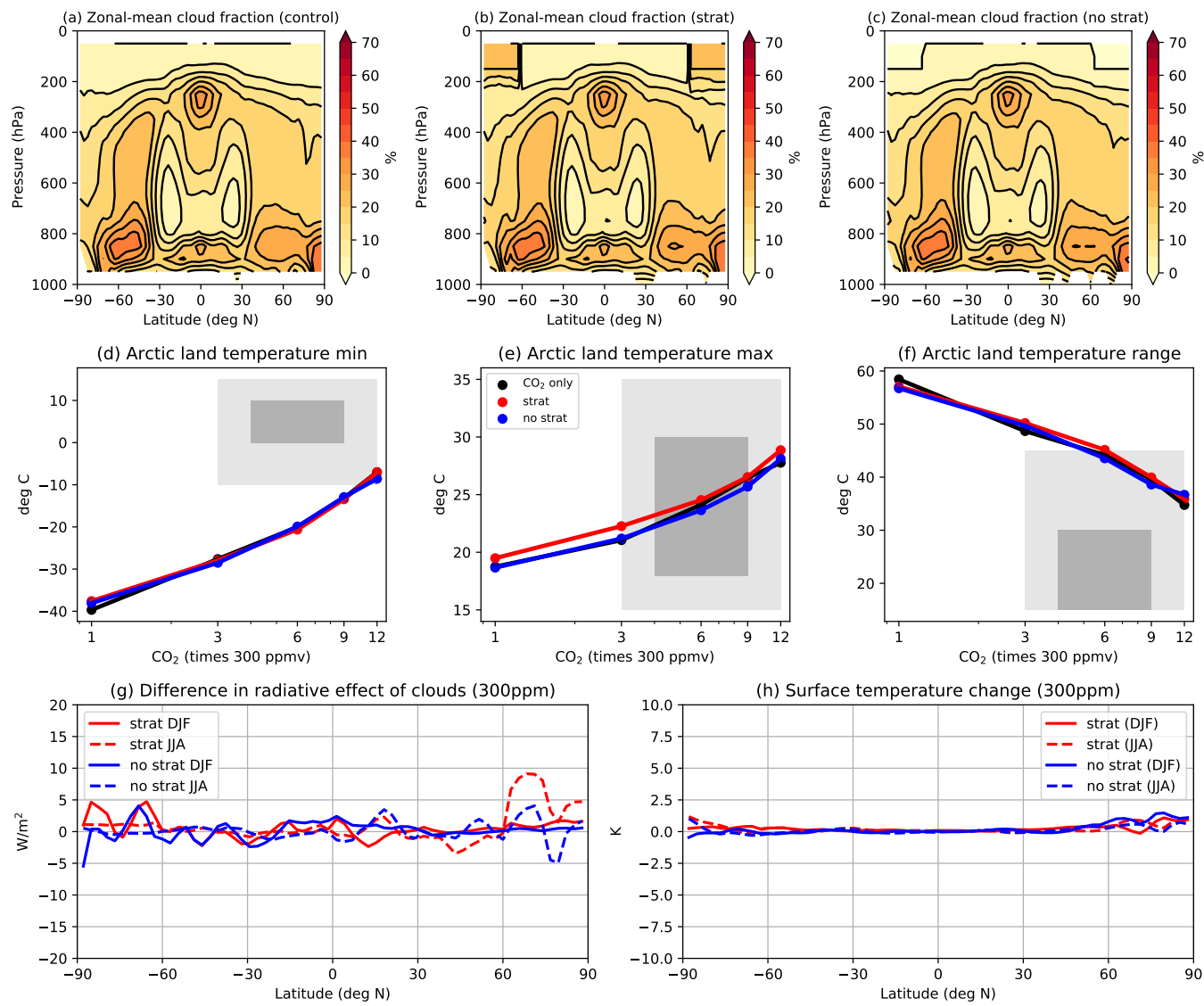

Figure 6. Prescribed Arctic stratospheric cloud experiments. Zonal-mean annual-mean cloud fraction for the control (a), increased stratospheric cloud (b), no stratospheric cloud (c) simulations at $300 \mathrm{ppm}$. Monthly minimum (d), maximum (e), and range (f) of Arctic land surface temperature for all three sets of simulations. The difference in radiative effect of clouds $(\mathrm{g})$ and surface temperature change $(\mathrm{h})$ between the prescribed cloud and control experiments at $300 \mathrm{ppm}$ for Northern hemisphere winter (DJF) and summer (JJA). In panels (d), (e), and (f), the dark grey represents the values derived from Eberle et al. (2010), and the light grey is a larger interval to account for the uncertainty in proxy values. 
(a) Surface temperature (ocean)

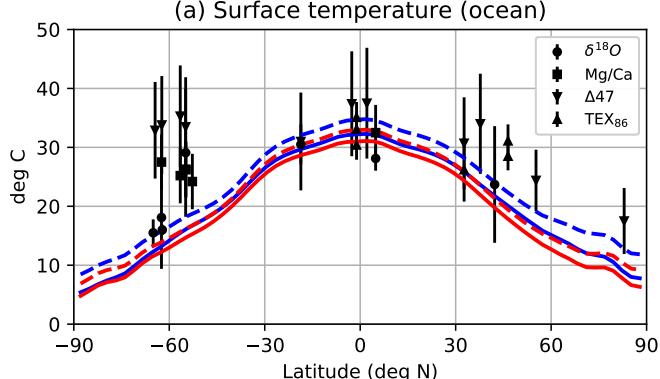

(c) Surface temperature (land, $>70$ lat)

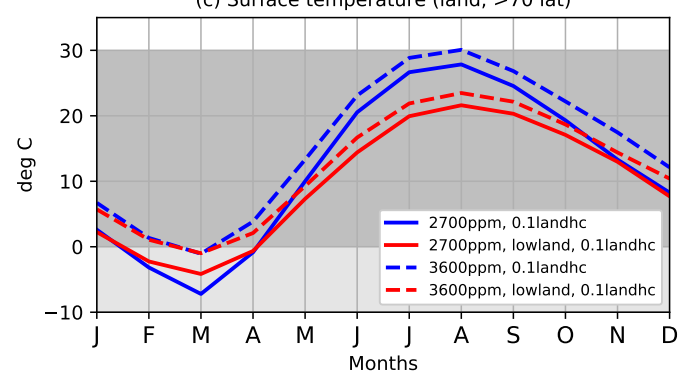

(b) Surface temperature (land)

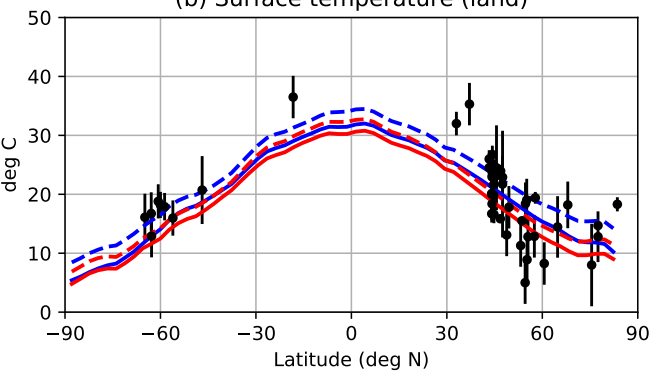

Figure 7. Increased land surface heat capacity experiments. Ocean (a) and land (b) annual-mean zonalmean surface temperature, and seasonality of Arctic land temperature (c) for simulations with higher land surface heat capacity (blue) and with higher land surface heat capacity and additional high-latitude low land clouds (red) at 2700 ppm (solid) and 3600 ppm (dashed). In panels (a) and (b), the proxy values for ocean surface temperatures are from Zhu et al. (2019) and the land surface temperatures are from Huber and Caballero (2011). In panel (c), the dark grey represents the values derived from Eberle et al. (2010), and the light grey is a larger interval to account for the uncertainty in proxy values.

the right magnitude and phase for the climate of today, though summer temperatures may have a warm bias because of the absence of snow in these simulations.

The characteristics of the land surface were likely quite different in the Eocene, especially at high latitudes where frozen soil and ice is replaced by abundant vegetation and possibly swamps and lakes. We therefore explore the sensitivity of our results to an increase in land surface heat capacity. Specifically, we set the mixed layer depth over land to $2 \mathrm{~m}$ instead of $0.2 \mathrm{~m}$ and to see how this affects the seasonal cycle at high $\mathrm{CO}_{2}$ levels. The increase in the 'mixed layer depth' of land to $2 \mathrm{~m}$ does not substantially change the zonal-mean annual-mean surface temperature (fig. 7a and b compared to fig. 2a and b). However, the seasonal cycle of Arctic land temperature is almost consistent with proxies (dark grey box) at $2700 \mathrm{ppm}$ and fully consistent with proxies at $3600 \mathrm{ppm}$ (fig. 7c).

Since the increased prescribed low clouds over land seemed a promising way to get a climate consistent with proxies (fig. 4), we also test a higher land surface heat capacity with increased prescribed low clouds over land. This does not substantially change the winter Arctic land temperature, it does however decrease the summer Arctic land temperature (fig. 7c) by increasing the albedo (fig. $4 \mathrm{~g}$ ).

\section{Ocean heat transport}

An increase in ocean heat transport has been sensibly posited to explain the reduced equatorto-pole temperature difference in the early Eocene climate. For example, Hotinski and Toggweiler (2003), using a diffusive atmospheric energy balance model, argued that an open Tethyan 
(a) Surface temperature

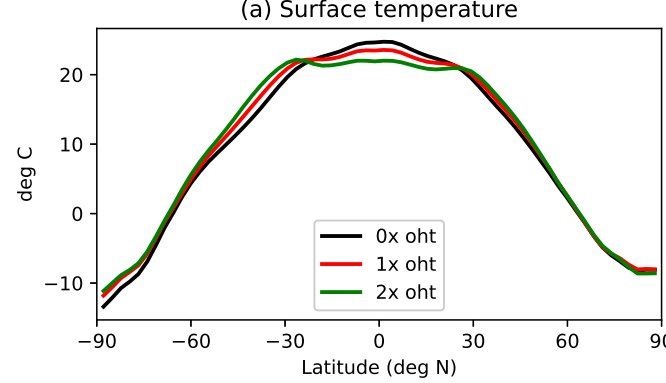

(c) Ocean q-flux (1xoht, $\mathrm{W} / \mathrm{m}^{2}$ )

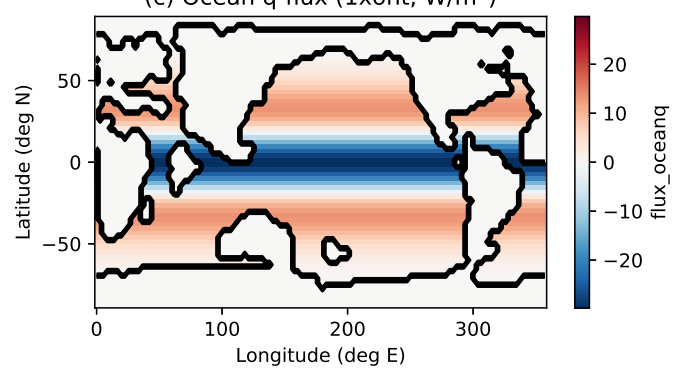

(b) Surface temperature (land, >70 deg)

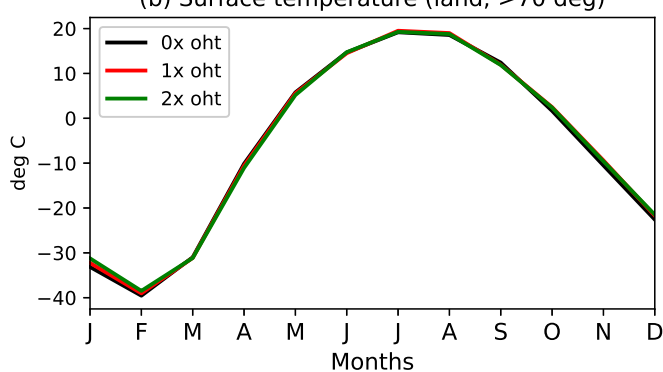

(d) Ocean energy flux (PW)

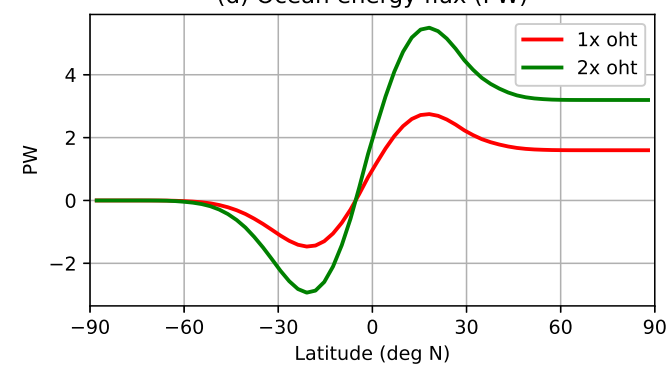

Figure 8. Ocean heat transport experiments. (a) Zonal-mean surface temperature and (b) land surface temperature poleward of $70 \mathrm{deg} \mathrm{N}$ for simulations with $0 \mathrm{x}, 1 \mathrm{x}$, and $2 \mathrm{x}$ the ocean $\mathrm{q}$-flux shown in (c), and corresponding ocean energy flux in (d). Note that since land masses are not taken into consideration in the ocean energy flux calculation, the integration of the q-flux does not reach 0 at the North pole.

Passage could reduce the temperature difference between high and low latitudes by between $5^{\circ} \mathrm{C}$ and $9^{\circ} \mathrm{C}$. However, other studies that use dynamical, three-dimensional atmospheric models have tended to find that changes in ocean heat transport are largely compensated by changes in atmospheric energy transport and the surface temperature is then largely unaltered, even over the ocean (Farneti \& Vallis, 2013; Rencurrel \& Rose, 2020).

We explore the importance of ocean heat transport by imposing a meridional heat flux (a 'q-flux') to the slab ocean that mimics equator-to-pole energy transport by the ocean, as in fig. 8c. The flux is such as to give an ocean meridional energy flux of about 2.5 Petawatts in the Northern hemisphere in the $1 \mathrm{x}$ experiment (fig. 8d). (Note that since land masses are not taken into consideration in the ocean energy flux calculation, the integration of the q-flux does not exactly reach zero at the North pole (fig. 8d).) We then double the magnitude of the flux; these changes are considerably larger than the changes that might be expected in an Eocene climate. Perhaps surprisingly, although consistent with the above-referenced studies, the imposed ocean heat transport has only a modest effect on the surface temperature (fig. 8a) and the Arctic land surface temperature is unchanged (fig. 8b). This is not to say that the ocean heat flux has no effect; rather, if the atmosphere is responding by changing its meridional energy flux then the intensity of its circulation (and hence such things as the mid-latitude storm tracks) will change correspondingly; however, we do not explore that here.

\section{Conclusion and Discussion}

In this paper we have explored the Eocene climate using a very flexible climate model that allows us to explore in a controlled fashion the individual and combined effects of changes in cloudiness, surface properties, ocean heat transport, and $\mathrm{CO}_{2}$ concentration. As well as comparing the simulation results to proxy estimates of the annual-mean zonal-mean surface temperature we have explored the factors influencing the seasonality of high-latitude land surface 
temperature, with many of the proxy measurements taken from Eberle et al. (2010). Simulating the seasonality of the Eocene climate (and past climates generally) is quite a severe test of the verisimilitude of model simulations, since it cannot be easily tuned to observations simply by varying $\mathrm{CO}_{2}$ levels without at the same time potentially giving less satisfactory annual mean temperatures.

The relative simplicity and flexibility of our climate model (compared, for example, with 'comprehensive' models used for global warming studies) allows us to explore the effects of changes in parameterizations or physical properties, recognizing the incompleteness of the proxy data (compared to observations of today) and the uncertain accuracy of parameterizations in climate models especially when applied to a different climate. The radiation scheme used in our model (SOCRATES, Manners et al., 2017) is, however, quite accurate for $\mathrm{CO}_{2}$ concentrations up to 32 times present day values. Our reference simulation - by which we mean simulations in which we change only the $\mathrm{CO}_{2}$ levels and leave other cloud cover and albedo unaltered - at $12 \times 300 \mathrm{ppm}$ is reasonably close to values suggested by the proxies, certainly in the annual mean. A change in planetary albedo can occur do to changes in cloud distribution or in surface properties such as ice cover and vegetation. Since these are quite uncertain for the Eocene period, we test how a 33\% reduction in surface albedo affects the global climate and find that it has a similar gross effect to increasing the $\mathrm{CO}_{2}$ levels (as also noted by Carlson and Caballero (2017) for example). In our simulations, the simulation with a 33\% reduction in surface albedo has roughly the same temperature at $2700 \mathrm{ppm}$ as the reference $3600 \mathrm{ppm}$ simulation.

More difficulty arises in simulating the seasonal cycle, and in particular in obtaining winter temperatures that are more-or-less consistent with the proxies without going to $\mathrm{CO}_{2}$ levels higher than observations suggest and which in turn leads to summer temperatures that are too high. Varying the cloud amounts is one way that better agreement can be achieved, and given the very different climate of the Eocene, different cloud regimes are certainly plausible and not necessarily captured in GCMs. To this end, we explored the effects of prescribing various cloud distributions over land and/or ocean. Prescribing additional high clouds over the Arctic ocean, as might occur if there were enhanced convective activity in the warmer climate, has only a small impact on Arctic land temperatures in our simulations and is not a major factor in better satisfying the proxies. Similarly, increasing stratospheric clouds also has a relatively small effect. However, the presence of low clouds over land can have a larger effect, with result depending on the season and the $\mathrm{CO}_{2}$ level. Prescribing additional low clouds over Arctic land increases winter Arctic land temperatures for low $\mathrm{CO}_{2}$, but has little effect at high $\mathrm{CO}_{2}$ since the additional greenhouse effect is then relatively small. However, the increased low cloud reduces summer Arctic land temperatures for all $\mathrm{CO}_{2}$ levels, bringing Arctic land seasonality closer to the proxies.

The physical mechanisms whereby cloud cover could change in an Eocene climate are less clear. We found that the land evaporative resistance (essentially a measure of the wetness of the surface) had a large impact on low cloud formation over land, with increasing wetness leading to more low cloud. This is a plausibly important effect, given that the high latitude land surface in the Eocene may have been dotted with lakes and rainforest-like vegetation. Nevertheless, even with this effect, the only way to make the Arctic land above freezing year-round is to increase the land surface heat capacity over its present value by a factor of 10 . This, too, is a plausible effect given the difference in land-surface properties in the Eocene compared to those of today. If we additionally prescribe increased low land clouds, the winter Arctic land temperature is not affected (at high $\mathrm{CO}_{2}$ levels), but the summer Arctic land temperature is reduced (for all $\mathrm{CO}_{2}$ levels). Finally, we note that, perhaps surprisingly, even large changes in ocean heat transport have very little impact on the zonal-mean surface temperature and Arctic land temperature seasonality (fig. 8). This is largely consistent with previous studies (Farneti \& Vallis, 2013; Rencurrel \& Rose, 2020).

There are, evidently, various pathways to get an Eocene climate simulation that is consistent with proxies: 
- By increasing $\mathrm{CO}_{2}$ levels to $3600 \mathrm{ppm}$ (fig. 1), which is slightly higher than what is suggested by recent proxies (Anagnostou et al., 2020), the surface temperature is within proxy bounds (fig. 2).

- By reducing the surface albedo by about one third, the temperature is within proxy bounds (fig. 3) for $2700 \mathrm{ppm}$ instead of $3600 \mathrm{ppm}$.

- Adding low clouds over land reduces summer Arctic land temperatures for all $\mathrm{CO}_{2}$ levels and increases winter Arctic land temperatures only al low $\mathrm{CO}_{2}$ levels. Thus, at the higher levels of $\mathrm{CO}_{2}$ appropriate for an Eocene climate, low clouds reduce the seasonality and help to bring the climate closer to proxies (fig. 4).

- Increasing the surface heat capacity of land has little effect on the meridional gradient in temperature, but reduces the Arctic land seasonality such that at $3600 \mathrm{ppm}$, the land surface temperature is above freezing year-round (fig. 7).

Given the relatively limited measurements, and the potentially similar effects that some of the changes have (e.g., reduced albedo vs increased $\mathrm{CO}_{2}$, increased low clouds and increased surface heat capacity), it is difficult to say what the 'correct' set of parameters is that can reproduce an Eocene climate. Undoubtedly, an increased level of $\mathrm{CO}_{2}$ is needed, likely to values of above $1800 \mathrm{ppm}$ in order to reach the observed temperatures, even with the uncertainties present in those. A more precise value of required $\mathrm{CO}_{2}$ levels cannot readily be estimated based on annual average considerations alone, but the seasonality provides a very useful additional constraint on model simulations. Our most plausible simulations arise with a $\mathrm{CO}_{2}$ level of around $2700 \mathrm{ppm}$ with additional low cloud prescribed over land and a higher high latitude heat capacity (fig. 7). These are all plausible effects, given the likely change in surface properties (no sea ice, a wet, unfrozen land surface with increased vegetation and possible lakes) but we cannot be definitive. We also find that our reference $3600 \mathrm{ppm}$ simulation and the $2700 \mathrm{ppm}$ simulation with a $33 \%$ reduction in surface albedo are viable simulations of an Eocene climate, although such a reduction in albedo is probably larger than could plausibly happen. Additional proxy measurements of seasonal information and surface properties, alongside more comprehensive simulations would further help reduce the uncertainty of both model parameterizations and the Eocene climate itself.

Finally, we draw some more general conclusions. The reduced equator-to-pole temperature gradient and much warmer winters over land of warm past climates can, to a first approximation, be explained by robust, known processes (e.g., changes in lapse rate in warmer climates, Planck feedbacks) and those effects can be captured by modern climate models, as both our results and those from the DeepMIP ensemble suggest. The proxies are not exactly matched, but the difference is not wholly unreasonable and do not suggest truly 'unknown physics'. Further, the reduced temperature gradient is likely not the result of a wholesale change in the general circulation of the atmosphere - the mid-troposphere temperature gradient need be little altered, for example. But having said that, care should be taken in using the Eocene to constrain the equilibrium climate sensitivity (to a doubling of $\mathrm{CO}_{2}$ levels) of today's climate, for even if proxy temperature measurements were exact, effects not present in today's climate come into play. Purely radiative effects imply that the ECS will increase somewhat as temperature increases, and cloud and other feedbacks (both positive and negative) that are quantitatively different from those of today may arise in very warm climates, rendering extrapolation imprecise at best.

\section{Acknowledgments}

We wish to thank all the Isca team for many discussions about climate and modelling, especially Stephen Thomson and Ruth Geen for help with the model setup and analysis. We also thank Eli Tziperman and Camille Hankel for a number of fruitful conversations about polar climates and clouds. This work was supported by NERC grant number NE/T00942X/1, under a NERC-NSF partnership named "Dynamics of Warm Past and Future Climates". The code 
${ }_{464}$ to reproduce the figures is available at https://github.com/matthewjhenry/eocene and 465 the data is available at https://zenodo.org/record/5591825 (Henry \& Vallis, 2021a). 


\section{References}

Abbot, D. S., \& Tziperman, E. (2008). Sea ice, high-latitude convection, and equable climates. Geophysical Research Letters, 35(3).

Anagnostou, E., John, E. H., Babila, T., Sexton, P., Ridgwell, A., Lunt, D. J., . . F Foster, G. (2020). Proxy evidence for state-dependence of climate sensitivity in the eocene greenhouse. Nature communications, 11(1), 1-9.

Burke, K., Williams, J., Chandler, M., Haywood, A., Lunt, D., \& Otto-Bliesner, B. (2018) Pliocene and Eocene provide best analogs for near-future climates. Proceedings of the National Academy of Sciences, 115(52), 13288-13293.

Carlson, H., \& Caballero, R. (2017). Atmospheric circulation and hydroclimate impacts of alternative warming scenarios for the Eocene. Climate of the Past, 13(8), 1037-1048.

Carmichael, M. J., Lunt, D. J., Huber, M., Heinemann, M., Kiehl, J., LeGrande, A., . . . others (2016). A model-model and data-model comparison for the early Eocene hydrological cycle. Climate of the Past, 12(2), 455-481.

Cronin, T. W., \& Jansen, M. F. (2016). Analytic radiative-advective equilibrium as a model for high-latitude climate. Geophysical Research Letters, 43(1), 449-457.

Cronin, T. W., Li, H., \& Tziperman, E. (2017). Suppression of Arctic air formation with climate warming: Investigation with a two-dimensional cloud-resolving model. Journal of the Atmospheric Sciences, 74(9), 2717-2736.

Cronin, T. W., \& Tziperman, E. (2015). Low clouds suppress Arctic air formation and amplify high-latitude continental winter warming. Proceedings of the National Academy of Sciences, 112(37), 11490-11495.

Eberle, J. J., Fricke, H. C., Humphrey, J. D., Hackett, L., Newbrey, M. G., \& Hutchison, J. H. (2010). Seasonal variability in arctic temperatures during early eocene time. Earth and Planetary Science Letters, 296(3-4), 481-486.

Farneti, R., \& Vallis, G. K. (2013). Meridional energy transport in the coupled atmosphereocean system: Compensation and partitioning. Journal of climate, 26(18), 71517166.

Frierson, D. M. (2007). The dynamics of idealized convection schemes and their effect on the zonally averaged tropical circulation. Journal of Atmospheric Sciences, 64(6), 1959-1976.

Graversen, R. G., \& Wang, M. (2009). Polar amplification in a coupled climate model with locked albedo. Climate Dynamics, 33(5), 629-643.

Greenwood, D. R., \& Wing, S. L. (1995). Eocene continental climates and latitudinal temperature gradients. Geology, 23(11), 1044-1048.

Henry, M., Merlis, T. M., Lutsko, N. J., \& Rose, B. E. (2021). Decomposing the Drivers of Polar Amplification with a Single-Column Model. Journal of Climate, 34(6), 23552365.

Henry, M., \& Vallis, G. K. (2021a). Idealized GCM dataset for "Different Pathways to an Early Eocene Climate" by Matthew Henry and Geoffrey K. Vallis. Zenodo. doi: 10 .5281 /zenodo.5591825

Henry, M., \& Vallis, G. K. (2021b). Reduced High-Latitude Land Seasonality in Climates with Very High Carbon Dioxide. Journal of Climate, 1-38.

Holland, M. M., \& Bitz, C. M. (2003). Polar amplification of climate change in coupled models. Climate Dynamics, 21(3), 221-232.

Hotinski, R., \& Toggweiler, J. (2003). Impact of a Tethyan circumglobal passage on ocean heat transport and "equable" climates. Paleoceanography, 18(1).

Hu, Z., Cronin, T. W., \& Tziperman, E. (2018). Suppression of Cold Weather Events over High-Latitude Continents in Warm Climates. Journal of Climate, 31(23), 9625-9640.

Huber, M., \& Caballero, R. (2011). The early Eocene equable climate problem revisited. Climate of the Past, 7(2), 603-633.

Huber, M., Sloan, L. C., \& Shellito, C. (2003). Early paleogene oceans and climate: A fully coupled modeling approach using the ncar ccsm. Geological Society of America Special Papers, 369, 25-47. 
Hwang, Y.-T., Frierson, D. M. W., \& Kay, J. E. (2011). Coupling between Arctic feedbacks and changes in poleward energy transport. Geophysical Research Letters, 38, L17704.

Kiehl, J. T., \& Shields, C. A. (2013). Sensitivity of the Palaeocene-Eocene Thermal Maximum climate to cloud properties. Philosophical Transactions of the Royal Society A: Mathematical, Physical and Engineering Sciences, 371(2001), 20130093.

Liu, Q., Collins, M., Maher, P., Thomson, S. I., \& Vallis, G. K. (2020). Simcloud version 1.0: a simple diagnostic cloud scheme for idealized climate models. Geoscientific Model Development Discussions, 1-39.

Lunt, D., Bragg, F., Chan, W.-L., Hutchinson, D., Morozova, P., Ladant, J.-B., . . . others (2020). Model intercomparison of early Eocene climatic optimum (EECO) large-scale climate features and comparison with proxy data. Climate of the Past.

Lunt, D. J., Bragg, F., Chan, W.-L., Hutchinson, D. K., Ladant, J.-B., Morozova, P., . . others (2021). Deepmip: Model intercomparison of early eocene climatic optimum (eeco) large-scale climate features and comparison with proxy data. Climate of the Past, 17(1), 203-227.

Manners, J., Edwards, J. M., Hill, P., \& Thelen, J.-C. (2017). SOCRATES: Suite Of Community RAdiative Transfer codes based on Edwards and Slingo (Tech. Rep.). Exeter, UK: UK Met Office.

Merlis, T. M., Schneider, T., Bordoni, S., \& Eisenman, I. (2013). Hadley circulation response to orbital precession. part ii: Subtropical continent. Journal of climate, 26(3), 754-771.

Pearson, P. N., van Dongen, B. E., Nicholas, C. J., Pancost, R. D., Schouten, S., Singano, J. M., \& Wade, B. S. (2007). Stable warm tropical climate through the eocene epoch. Geology, 35(3), 211-214.

Pierrehumbert, R. T. (2010). Principles of planetary climate. Cambridge University Press.

Rencurrel, M. C., \& Rose, B. E. (2020). The efficiency of the Hadley cell response to wide variations in ocean heat transport. Journal of Climate, 33(5), 1643-1658.

Sloan, L. C., \& Pollard, D. (1998). Polar stratospheric clouds: A high latitude warming mechanism in an ancient greenhouse world. Geophysical Research Letters, 25(18), 3517-3520.

Taylor, P. C., Boeke, R. C., Boisvert, L. N., Feldl, N., Henry, M., Langen, P. L., . . Tan, I. (2021). Process drivers, inter-model spread, and the path forward: A review of amplified arctic warming. EarthArxiv Preprint. doi: https://doi.org/10.31223/X5VS6C

Thomson, S. I., \& Vallis, G. K. (2019). The effects of gravity on the climate and circulation of a terrestrial planet. Quarterly Journal of the Royal Meteorological Society, 145(723), 2627-2640.

Tierney, J. E., Poulsen, C. J., Montañez, I. P., Bhattacharya, T., Feng, R., Ford, H. L., . . others (2020). Past climates inform our future. Science, 370(6517).

Vallis, G. K., Colyer, G., Geen, R., Gerber, E., Jucker, M., Maher, P., . . Thomson, S. I. (2018). Isca, v1. 0: A framework for the global modelling of the atmospheres of earth and other planets at varying levels of complexity. Geoscientific Model Development, 11(3), 843-859.

Zhu, J., Poulsen, C. J., \& Tierney, J. E. (2019). Simulation of Eocene extreme warmth and high climate sensitivity through cloud feedbacks. Science Advances, 5(9), eaax1874. 